\title{
Correction to: Intracranial MR Angiography
}

Nicoletta Anzalone and Armando Tartaro

\section{Correction to:}

Chapter 7 in: G. Schneider et al. (eds.), Magnetic Resonance Angiography, https://doi.org/10.1007/978-88-470-0352-1_7

The original version of the book was inadvertently published with an incorrect sentence in chapter 7 on page 103 under the section "Normal Anatomy". The sentence has been corrected as given below.

\section{From:}

The internal carotid artery (ICA) originates from the bifurcation of the common carotid artery and penetrates the skull base through the jugular foramen.

To:

The internal carotid artery (ICA) originates from the bifurcation of the common carotid artery and penetrates the skull base through the carotid canal. 